\title{
The Influence of Agricultural Farmers' Entrepreneurial Behavior on the Business Performance of Dairy Farmers in Andhra Pradesh
}

\author{
Gangu Naidu Mandala ${ }^{1, *}$, Meenakshi Verma ${ }^{1}$, Anuj Verma ${ }^{1}$, Suresh Sirisetti $^{2}$, \\ Venkata Ramakrishna Rao Gandreti ${ }^{3}$ \\ ${ }^{1}$ Symbiosis Institute of Business Management, Nagpur, Symbiosis International Deemed to be University, India \\ ${ }^{2}$ GITAM Institute of Management, GITAM Deemed to be University, Visakhapatnam, India \\ ${ }^{3}$ Vignan's Institute of Engineering for Women, Visakhapatnam, India
}

Received January 31, 2021; Revised March 18, 2021; Accepted March 31, 2021

\section{Cite This Paper in the following Citation Styles}

(a): [1] Gangu Naidu Mandala, Meenakshi Verma, Anuj Verma, Suresh Sirisetti, Venkata Ramakrishna Rao Gandreti , "The Influence of Agricultural Farmers' Entrepreneurial Behavior on the Business Performance of Dairy Farmers in Andhra Pradesh," Universal Journal of Agricultural Research, Vol. 9, No. 2, pp. 57 - 61, 2021. DOI: 10.13189/ujar.2021.090204.

(b): Gangu Naidu Mandala, Meenakshi Verma, Anuj Verma, Suresh Sirisetti, Venkata Ramakrishna Rao Gandreti (2021). The Influence of Agricultural Farmers' Entrepreneurial Behavior on the Business Performance of Dairy Farmers in Andhra Pradesh. Universal Journal of Agricultural Research, 9(2), 57 - 61. DOI: 10.13189/ujar.2021.090204.

Copyright $\bigcirc 2021$ by authors, all rights reserved. Authors agree that this article remains permanently open access under the terms of the Creative Commons Attribution License 4.0 International License

Abstract In the present worldwide serious business and industrialization, entrepreneurs can assume a larger part. The innovative movement has an immediate bearing on the country's financial development. It fills in as an impetus during the time of industrialization and monetary turn of events. Entrepreneurship is the focal power of monetary action, which is needed for the advancement of the country. The innovative characteristics contribute to pay, fearlessness and a wellspring of accomplishment. Entrepreneurs are the critical people of any country in advancing financial development and innovative change. The dairy area plays a multi-faceted part in the financial improvement of country family units. Animals' raising emphatically affects value regarding pay; and work and neediness decreases in provincial territories. Dairy is a significant aspect of farming development and is additionally considered as a possible area for trade income. India has the biggest milk maker of milk on the planet. Dairy endeavor turns out to be nonstop revenue as well as gives great business freedoms to the poor provinces. Current investigation was conducted to know the innovative conduct of dairy farmers in Vizianagaram District of Andhra Pradesh in 2020 with 240 dairy entrepreneurs. The significant discoveries of the investigation were that a large portion of the prepared dairy farmers were in the medium to the high enterprising class and that lion's share of dairy farmers had an undeniable degree of pioneering qualities viz: self-confidence, achievement motivation, innovativeness, and risk-orientation.

Keywords Dairy Farmer, Entrepreneurial Behaviour, Livestock Production, Milch Animal

JEL Codes: J43, L26, L31

\section{Introduction}

There are, in real sense, a handful and many various meanings of 'the business person' and the idea of 'entrepreneurship'. Ashilina, H., Baga, L.M., Jahroh, S. [1] Specialists and authors regularly appear to pick the definition that best fits the territory they are talking about. We have expressly connected entrepreneurship to the 
ability for using effectively inventive thoughts in a financially serious market. Frese, M., Brantjes, A., Hoorn, R. [2] The way that people work in general society and non-benefit areas can be extremely ambitious. Notable and strategy make terms entrepreneurship allude to business conduct identified with advancement and development. Manev, I.M., Gyoshev, B.S., Manolova, T.S. [3] For our motivations, entrepreneurs might be extensively characterized as individuals who deal with a business with the expectation of extending that business by applying some type of advancement and with the authority and administrative limit with regards to accomplishing their objectives. Despite solid rivalry from different firms, most firms' motivation is enormous and little. Yadav, D.S., Chahal, V.P., Kumar, A., Singh, U. [4] The general point of this course, along these lines, is to furnish you with freedom to consider and ponder individual perspectives engaged with changing an imaginative thought into a pioneering item.

Visiting numerous homesteads every year furnishes me with the one-of-a-kind chance to notice contrasts between ranches. The external numerous ranches work in an unexpected way, yet there is an on-going theme among the best dairy makers.

The following are a portion of the normal qualities I have seen on the more fruitful ranches.

Top dairy makers have an enthusiasm for their work and an inspirational disposition toward what's to come. Nath, D., Kumar, A [5] the main component of effective ranches is the inspirational disposition of proprietors and directors. Thakur, D., Chandra, M. [6]) Despite the fact that they may not understand what's in store, they think cultivating can be a decent business and furnish them with the way of life they appreciate.

\section{Research Methodology}

Vizianagaram area of Andhra Pradesh was purposively chosen for current examination as it had the greatest milch ox-like populace. Four squares of Vizianagaram locale: Bobbili, Parvathipuram, Gajapathinagaram, and Ramabadrapuram were chosen purposively and from each square; five towns were chosen haphazardly. From every town, 12 dairy farmers were chosen arbitrarily to establish an all-out example size of 240 farmers. The information was gathered through personally meeting the respondents with the assistance of a pre-tried organized meeting plan with the deference of the goals of the investigation. The gathered information was scored, tabulated, and analyzed by using frequency, percentage, mean, standard deviation, and correlation.
Table 1. Entrepreneurial behaviour of dairy farmers $n=240$

\begin{tabular}{|c|c|c|c|c|}
\hline $\begin{array}{l}\text { S. } \\
\text { No }\end{array}$ & Variable & Category & Frequency & $\%$ \\
\hline \multirow{4}{*}{1} & \multirow{4}{*}{$\begin{array}{l}\text { Achievement } \\
\text { motivation }\end{array}$} & Low & 50 & $20.8 \%$ \\
\hline & & Medium & 110 & $45.8 \%$ \\
\hline & & High & 80 & $33.4 \%$ \\
\hline & & Total & 240 & $100 \%$ \\
\hline \multirow{4}{*}{2} & \multirow{4}{*}{ Risk orientation } & Low & 36 & $15 \%$ \\
\hline & & Medium & 120 & $50 \%$ \\
\hline & & High & 84 & $35 \%$ \\
\hline & & Total & 240 & $100 \%$ \\
\hline \multirow{4}{*}{3} & \multirow{4}{*}{ Planning ability } & Poor & 20 & $8.4 \%$ \\
\hline & & Moderate & 144 & $60 \%$ \\
\hline & & Good & 76 & $31.6 \%$ \\
\hline & & Total & 240 & $100 \%$ \\
\hline \multirow{4}{*}{4} & \multirow{4}{*}{$\begin{array}{c}\text { Decision making } \\
\text { ability }\end{array}$} & Low & 32 & $13.4 \%$ \\
\hline & & Medium & 132 & $55 \%$ \\
\hline & & High & 76 & $31.6 \%$ \\
\hline & & Total & 240 & $100 \%$ \\
\hline \multirow{4}{*}{5} & \multirow{4}{*}{$\begin{array}{l}\text { Communication } \\
\text { skills }\end{array}$} & Low & 72 & $30 \%$ \\
\hline & & Medium & 112 & 46. $\% 0$ \\
\hline & & High & 56 & $23 . \% 0$ \\
\hline & & Total & 240 & $100 \%$ \\
\hline \multirow{4}{*}{6} & \multirow{4}{*}{ Self confidence } & Low & 32 & $13.4 \%$ \\
\hline & & Medium & 128 & $53.3 \%$ \\
\hline & & High & 80 & $33.3 \%$ \\
\hline & & Total & 240 & $100 \%$ \\
\hline \multirow{4}{*}{7} & \multirow{4}{*}{ Adoption prosperity } & Low & 52 & $21.6 \%$ \\
\hline & & Medium & 124 & $51.7 \%$ \\
\hline & & High & 64 & $26.7 \%$ \\
\hline & & Total & 240 & $100 \%$ \\
\hline \multirow{4}{*}{9} & \multirow{4}{*}{ Profit orientation } & Low & 66 & $27.5 \%$ \\
\hline & & Medium & 130 & $54.2 \%$ \\
\hline & & High & 44 & $18.4 \%$ \\
\hline & & Total & 240 & $100 \%$ \\
\hline \multirow{4}{*}{10} & \multirow{4}{*}{ Coordinating ability } & Low & 24 & $10 \%$ \\
\hline & & Medium & 76 & $31.7 \%$ \\
\hline & & High & 140 & $58.3 \%$ \\
\hline & & Total & 240 & $100 \%$ \\
\hline \multirow{4}{*}{11} & \multirow{4}{*}{ Cosmo politeness } & Low & 54 & $22 . \% 0$ \\
\hline & & Medium & 128 & $53.4 \%$ \\
\hline & & High & 58 & $24.1 \%$ \\
\hline & & Total & 240 & $100 \%$ \\
\hline \multirow{3}{*}{12} & \multirow{3}{*}{ Locus of control } & Internal & 136 & $56.7 \%$ \\
\hline & & External & 104 & $43.3 \%$ \\
\hline & & Total & 240 & $100 \%$ \\
\hline
\end{tabular}

Sources: Primary Data 


\section{Entrepreneurial Behaviour of Dairy Farmers}

The data in table 1 depicted the entrepreneurial behavior of dairy farmers comprised nine components, namely achievement motivation, risk orientation, planning ability, decision-making ability, communication skills, self-confidence, adoption prosperity, and profit orientation, coordinating ability, Cosmo politeness, and Locus of control (Singh, P., Sharma, K.C., Dahiya, N.S. [6]).

\section{Achievement Motivation}

Accomplishment inspiration is an immediate indicator of accomplishment applicable conditions. The discoveries uncovered that almost half $(45.8 \%)$ of the dairy farmers had a medium degree of accomplishment inspiration followed by respondents in the high class (33.4\%) and low classification (20.8\%). The likely purpose behind this pattern may be enthusiasm and obsession to get cost-adequately solid. The higher yearly pay may have urged them to set the higher goal.

\section{Risk Orientation}

The information in Table 1 demonstrated that the greatest number (half) of dairy farmers had a medium level followed by $35 \%$ of them had a high class of danger direction. Just $15 \%$ had a low class of danger direction. The plausible explanation behind the significant degree of danger taking limit on account of dairy proprietors might be the fact that there is a ton of interest for the milk as this is devoured by each family and brings a decent benefit delivering results like cheddar, curd, and margarine.

\section{Planning Ability}

Arranging capacity can address or forestall practically any basic issue in the most punctual courses of business venture improvement. Table 1 uncovered that the lion's share $(60 \%)$ of dairy farmers had a medium degree of preparation capacity, while $31.6 \%$ percent of them had high and $8.4 \%$ had a low degree of preparation capacity. The conceivable explanation is that the dairy cultivator had given significance to the exercises, which would turn out to be normal revenue later on.

\section{Decision-making Ability}

Dynamic is the way to recognize and choose, which is dependent on the qualities and inclinations of the leader (business visionary). Table 1 showed that the greatest number $(55 \%)$ of dairy farmers had a medium degree of dynamic capacity, though $31.6 \%$ of them had high and $13.4 \%$ had a low level of this quality. The expanded reaction in the high classification of dynamic is that most of the farmers had singular proprietorship status and were of the view that it was their self-choice to begin the undertaking.

\section{Communication Skills}

Correspondence is a primary ability that applies to each zone of a business venture. The information on this boundary shows that about half $(46.6 \%)$ of the dairy farmers had a medium degree of relational abilities, while more than one-fourth of (30\%) the dairy farmers had a low degree of relational abilities. Just $23.4 \%$ had high relational abilities. The plausible explanation behind the medium degree of relational abilities may be that lion's share of the business visionaries had prompted moderate cooperation in different social and augmentation exercises.

\section{Self-confidence}

Self-assurance implies an individual pass on trust in his own ability to finish an assignment or address a difficulty. In current investigation, the larger part (53.3\%) of dairy farmers had a medium degree of fearlessness while $33 \%$ of dairy farmers had a high $(33.3 \%)$ and $13.4 \%$ have a low degree of self-assurance. The likely explanation behind a significant degree of self-assurance may be that a medium degree of accomplishment inspiration, dynamic capacity, and selection inclination. Since dairy farmers had more serious danger taking a limit.

\section{Adoption Prosperity}

The information on this boundary portrayed in Table 1 uncovered that the greater part $(51.7 \%)$ of the dairy farmers were found to have a medium degree of reception flourishing, trailed by low (26.7\%) and significant level $(21.6 \%)$. The plausible purpose behind higher selection penchant might be that they were more educated having a high danger of taking a limit.

\section{Profit Orientation}

Benefit $\mathrm{t}$ direction coordinates the business visionary towards making a benefit tout of the venture. On account of benefits $t$ direction, it was seen in the examination that the greater part of them $(54.2 \%)$ of dairy farmers had a medium degree of benefits $\mathrm{t}$ direction followed by low $(27.5 \%)$ benefit $t$ direction. Subsequently, it could be presumed that the respondents have a medium degree of benefits $t$ direction on the grounds that the dairy farmers are not misusing the maximum capacity of dairy as an endeavor.

\section{Coordinating Ability}

The planning capacity and positive connections are essential to the accomplishment of the business visionary's 
undertaking. The outcomes in Table 1 portray that the greater part (58.3\%) of the dairy farmers had a significant degree of planning capacity, while more than one-fourth of $(31.7 \%)$ the dairy farmers had a low degree of organizing capacity. Just $10 \%$ had a high organizing capacity. It may be deduced from Table 1 that such planning capacity example exists because of acceptable social support and better training.

\section{Cosmopoliteness}

A medium degree of cosmopolites was controlled by $53.40 \%$ of the dairy farmers, while $24.10 \%$ of them had high and $22.50 \%$ had an undeniable degree of cosmopolites. The circulation of cosmopolites in the investigation may be attributed to moderate monetary conditions, prompting moderate support in different social and expansion exercises.

\section{Locus of Control}

Locus of control has a focal spot taking everything into account as it uncovers the internal desire of a business person. Table 1 showed that most $(56.7 \%)$ dairy farmers were having an outside locus of control while $43.3 \%$ of them had an interior locus of control. The likely explanation may be that dairy farmers in each regard of entrepreneurial attributes gave a positive indication for building up the dairy venture as fruitful good examples for different farmers (Nilo E. Padilla, Joe Ann G. Payne, Visitacion S. Simbulan, Ralph John S. Lapastura, Errol John A. Cadeliña [8]).

The outcomes in the Table 1 portrays that around three fourth of the dairy farmers $(68.4 \%)$ has a place with medium level entrepreneurial conduct, trailed by $18.3 \%$ having an undeniable degree of entrepreneurial conduct. However, $13.3 \%$ of the dairy rancher had a place with low entrepreneurial conduct.

Table 2. Distribution of dairy farmers according to their entrepreneur behaviour $(\mathrm{n}=240)$

\begin{tabular}{|c|c|c|c|}
\hline S. No & Categories & No. of respondents & $\mathbf{\%}$ \\
\hline 1 & Low (Up to 35) & 32 & $13.3 \%$ \\
\hline 2 & Medium (36 to 60) & 164 & $68.4 \%$ \\
\hline 3 & $\begin{array}{c}\text { High (61 and } \\
\text { Above ) }\end{array}$ & 44 & 18.30 \\
\hline
\end{tabular}

Sources: Primary Data

In Table 2, it shows that the legitimate reason of medium followed by high entrepreneurial conduct is that their sound monetary condition, higher land holding, advanced education level and higher logical direction. In any case, all the significant eleven parts of entrepreneurial conduct of dairy farmers together mirror their medium entrepreneurial conduct.
Table 3. Relationship between characteristics of dairy farmers with their entrepreneurial behaviour $(\mathrm{n}=240)$

\begin{tabular}{|l|c|c|}
\hline $\begin{array}{c}\text { S. } \\
\text { No. }\end{array}$ & Variables & $\begin{array}{c}\text { Correlation co-efficient ' } \mathbf{r} \text { ' } \\
\text { Value }\end{array}$ \\
\hline 1. & Age & $-0.2032^{*}$ \\
\hline 2. & Education & $0.4426^{*}$ \\
\hline 3. & Family size & $0.0356^{\mathrm{NS}}$ \\
\hline 4. & Occupation & 0.0461 \\
\hline 5. & Extension contact & $0.4757^{* *}$ \\
\hline 6. & Land holding & $0.3726^{*}$ \\
\hline 7. & Annual income & $0.3451^{* *}$ \\
\hline 8. & Innovativeness & $0.5217^{*}$ \\
\hline 9. & Livestock possession & $0.02520^{\mathrm{NS}}$ \\
\hline 10. & $\begin{array}{c}\text { Experience in } \\
\text { dairying }\end{array}$ & $0.6794^{* *}$ \\
\hline 11. & Economic motivation & $0.2580^{* *}$ \\
\hline 12. & Information seeking & $0.4216^{* *}$ \\
\hline
\end{tabular}

Sources: Primary Data

* And ** indicate significance of values at $\mathrm{P}=0.05$ and 0.01 , respectively; $\mathrm{NS}=$ Non-significant

\section{Relationship between Characteristics of Dairy Farmers with Their Entrepreneurial Behaviour}

In Table 3, it shows that out of twelve, eight factors of dairy farmers, specifically viz., instruction, landholding, imaginativeness have a positive and critical relationship at $0.05 \%$ degree of significance, though augmentation contact, yearly pay, the experience of dairying and financial inspiration and data looking for had a positive relationship at $0.01 \%$ degree of significance yet just age was contrarily huge, reaching a $0.01 \%$ degree of significance with their entrepreneurial conduct. Further, residual qualities, for example, family size, occupation, and animal ownership didn't display any huge relationship with their entrepreneurial conduct.

The period of dairy farmers was found to have a negative and critical relationship with their entrepreneurial conduct which decided the genuineness, flourishing, and carelessness to continue through to the end for unmitigated execution in any endeavor. The mature age dairy farmers were by and large deadpan and felt fought in existing conditions. In actuality, more youthful farmers were more ambitious, energetic penny-squeezing foreordained and made for flawlessness in the element. This may be the purpose behind a negative relationship between the period of dairy farmers and their entrepreneurial conduct.

Additionally, the schooling of dairy farmers had a positive and huge relationship with their entrepreneurial conduct. As to occupation, family size, occupation, and domesticated animal ownership, they didn't show any critical relationship with their entrepreneurial conduct. A vast part of dairy farmers were occupied with agribusiness alongside dairying which indicated less variety in their occupation as the purpose behind no critical relationship. 
Landholding and yearly pay of dairy farmers had a positive and huge relationship with their entrepreneurial conduct. The conceivable explanation behind the current finding may be that respondents with bigger property would have more freedom and possibilities to attempt to receive different logical adjustments. Subsequently, (Suren Kulshreshtha [9]) it is very conceivable that farmers with bigger landholding demonstrated devoted revenue to think about new practices and be more open to such thoughts. In this way prompting improved learning of acknowledgment, monetary inspiration, accomplishment inspiration, and data chasing, and efficient copy on their business visionaries had a positive and huge relationship with their entrepreneurial conduct. Considering dairying is an exceptionally gainful undertaking, business visionaries sure up-degree of monetary inspiration and they contend immovably to execute try in like manner expect sauce heightening.

Encounters in dairying positively affect entrepreneurial conduct, as they give the premise to dynamic capacity of an endeavour, which is a capacity to learn and adjust to evolving conditions. A positive critical relationship was found between data looking for dairy farmers and their entrepreneurial conduct. The consistent reasons may be that dairy farmers with data looking for conduct could be more intrigued by the most recent development and utilize it in their daily undertakings.

\section{Conclusions}

The investigation uncovered that lion's share (68.4\%) of dairy farmers had medium level entrepreneurial conduct which is an obvious sign of the tolerance of dairy cultivators. Endeavours for expanded mindfulness and information in dairy creation procedures through different imaginative augmentation strategies only intended for the objective gathering is critically required. This will assist they with obtaining every day specialized turns of events and the effect of the reception of those logical practices on their dairy business and work. Out of twelve, eight factors specifically viz., training, landholding, creativity augmentation contact, yearly pay, the experience of dairying, financial inspiration and data looking for had a positive and huge relationship; yet just age was adversely critical, corresponded with their entrepreneurial conduct. Subsequently, the financial and mental factors fundamentally impact the entrepreneurial conduct of dairy farmers because of better schooling, landholding, occupation, and yearly pay, insight in dairying, ingenuity, expansion contact, monetary inspiration, and data looking for dairy farmers.

\section{REFERENCES}

[1] Ashilina, H., Baga, L.M., Jahroh, S. The influence of farmers entrepreneurial behavior on the business performance of dairy farmers in West Bandung Regency, Indonesia, Journal of the International Society for Southeast Asian Agricultural Sciences, Volume 25, Issue 2, December 2019, Pages 143-154.

[2] Frese, M., Brantjes, A., Hoorn, R. Psychological success factors of small scale businesses in Namibia: The roles of strategy process, entrepreneurial orientation and the environment, (2002) Journal of Development Entrepreneurs hip, 7 (3), pp. 259-282.

[3] Manev, I.M., Gyoshev, B.S., Manolova, T.S., The role of human and social capital and entrepreneurial orientation for small business performance in a transitional economy, (2005) International Journal of Entrepreneurship and Innovation Management, 5 (3-4), pp. 298-318. doi: 10.1504/ijeim.2005. 006531 .

[4] Yadav, D.S., Chahal, V.P., Kumar, A., Singh, U. Entrepreneurial behaviour and constraints encountered by farm women in dairy enterprise, Indian Journal of Animal Sciences, Volume 84, Issue 10, 1 October 2014, Pages 1127-1132.

[5] Nath, D., Kumar, A. A comparative study of farm entrepreneurs of Mandi district of Himachal Pradesh (2008) Himachal Journal of Agricultural Research, 34 (2), pp. 73-78

[6] Thakur, D., Chandar, M. Gender based differential access to information among livestock owners and its impact on house hold milk production in Kangra district of Himachal Pradesh, (2006) Indian Journal of Dairy Science, 59 (6), pp. 401-404.

[7] Singh, P., Sharma, K.C., Dahiya, N.S. Entrepreneurial behaviour of dairy farmers in Western Rajasthan, Veterinary Practitioner, Volume 14, Issue 2, 2013, Pages 390-393

[8] Nilo E. Padilla, Joe Ann G. Payne, Visitacion S. Simbulan, Ralph John S. Lapastura, Errol John A. Cadeliña (2020). Capacity Building for Dairy Farmers towards Commercialization of Green Corn Silage, Haylage and Urea Molasses Mineral Block. Universal Journal of Agricultural Research, 8(6), 233 - 240. DOI: 10.13189/ujar.2020.080604.

[9] Suren Kulshreshtha (2020). Comparative Analysis of Adopted Rural Development Measures in Saskatchewan: Five Case Studies. Universal Journal of Agricultural Research, 8(3), 59 - 69. DOI: 10.13189/ujar.2020.080301. 